\title{
Exploring the Perfection Measures of Quality Management in Construction Site of Industrial and Civil Buildings
}

(Hangzhou Construction Engineering Group Co., Ltd. Hangzhou Zhejiang, 310013, China)

\section{Limitation in the Management of Construction Site of Industrial and Civil Buildings at Present Stage \\ 1.1 Lack of Sound Preparation of Construction}

Whether industrial or civil construction, construction site management is particularly important, and is closely related to the construction quality of the entire project. All good preparatory work of construction is the precondition for sound construction site management. Preparation if not done, will affect the coordination of later construction and the construction cost. In terms of the current situation of China's construction industry, many companies have not done a good job of preparation before construction, such as budget is not reasonable enough and construction drawings management system is not perfect enough.

\subsection{Lack of Attention to Safety Construction}

At present, most construction workers in our country have not been professionally trained and safety supervision is not in place, which are easy to cause a variety of security problems and pose serious threat to the safety of construction workers.

1.3 Lack of Effective Construction Materials Management

In the specific construction process, the effective management of construction materials is also very important. Construction materials are often in large quantities and in a wide range and the continuous emergence of a variety of new construction materials even have brought greater difficulty to the actual management. If there is no effective management, the construction site will be in chaos and will also cause some difficulties in management.

2 Measures to Improve On-site Quality Management of Industrial and Civil Buildings

\subsection{Develop a Reasonable Construction Program}

Construction must be carried out strictly in accordance with the pre-construction plans, which requires that construction program must be fully integrated with the specific construction environment and the actual situation. Then a most scientific and rational plan must be made combined with the construction management, construction and design personnel and other aspects. The final construction program can be formed only after a detailed discussion and research.

\subsection{Improve Construction Materials} Management

The management of construction materials can be preceded from the following aspects: firstly, the construction materials management plan and management personnel should be clearly defined before starting
Abstract: At the present stage, China's construction industry has achieved rapid development with the rapid development of our society and economy. In the construction of our country's construction industry, scientific and rational project construction management can not only effectively improve the safety quality of construction workers, strengthen the personnel management of construction workers, effectively reduce the accidents of construction projects, but also can save the cost of construction projects and improve the economic efficiency of construction enterprises to the greatest extent. In view of this, this paper first analyzes the existing problems in the management of industrial and civil construction site and puts forward corresponding solutions.

Key words: Industrial civil; Construction; Construction site; Quality management; Improvement measures

Published online: $30^{\text {th }}$ Nov, 2017 
construction. Only in this way can we better ensure that there is there is evidence from the actual management process; secondly, the managers should also be given some training and education to constantly improve their management awareness so that they fully understand their responsibilities in the work and the importance of the work. They should also continue to enhance their sense of legal management, so that they will not slacken in the specific management process; thirdly, after the construction materials have come into play, they should be strictly classified and stored according to different types before being put into use and the relevant factors should be fully considered to better ensure the safety of materials; finally, continuously improve the utilization rate of construction materials. A very strict schedule shall be developed in the specific use, and then construction workers shall carry out specific construction operations in accordance with the schedule to avoid waste of construction materials.

\subsection{Do a Good Job on the} Construction Site Equipment Management

Today's projects construction are inseparable from the extensive use of various construction machinery and equipment, which requires that the relevant staff should fully understand the specific operating skills and related functions of these equipment, fully understand its various operating methods, and continuously improve the utilization rate of the equipment in use before starting construction. After the equipment is put into use, the relevant staff should also carry out regular maintenance and overhaul and timely detect the hinder danger of the equipment and take appropriate measures to avoid those equipment problems affect the construction progress of the project. In addition, managers should also record the type and quantity of equipment in detail, try their best to prolong the service life of the equipment, and at the same time, try to reduce the cost as much as possible.

\subsection{Do a Good job on Construction} Site supervision and Management

The supervision and management of the construction is a very important link in the entire project quality management which require that strict supervision of the procurement of construction materials shall be carried out to better ensure the quality of material procurement and well meet the specific construction needs of the project; in addition, the construction staff should also be in some supervision, mainly the condition that whether there is illegal operation, Jerry-built or confusion construction. Only to ensure that the construction process and construction techniques have a certain standard, can better ensure the construction efficiency and construction quality.

\subsection{Do a Good Job of}

Construction Schedule Management

In the specific construction process, it is inevitable there will be power outages, water shortages and even some accidents. In the event of these uncontrollable special circumstances, the failure to take corresponding measures in time will have a very serious impact on the construction progress of the whole project. Therefore, we must do a good job of construction schedule management. First of all, make a sound contingency plan for various special cases in the construction. Second, we should also do a good job in communication and coordination between all construction departments and teams. In the case of special circumstances, it should promptly report and feedback to the higher authorities, and take appropriate solutions to better ensure the progress of the construction of the entire project.

$2.6 \quad$ Improve Construction Safety
Management

Usually the construction cycle of construction is longer and the amount of work is relatively large. The specific construction process is also susceptible to various external factors, posing a serious threat to the safety of construction workers. The following measures can be taken to continuously improve the safety management of the construction site: First of all, before the commencement of construction, a corresponding safety management department shall be set up and safety management personnel shall be elected to inspect and manage the construction site on a regular basis so as to avoid the occurrence of potential safety hazards at the construction site; second, constantly improve the safety protection equipment of construction site and all workers entering the construction site should wear the appropriate safety equipment. Thirdly, organize certain safety training and education activities for construction workers so as to continuously raise their awareness of safety and at the same time improve their technical level of safety construction.

All in all, the management of industrial and civil construction sites is systematic. Construction enterprises need to do a good job in all aspects of coordination for the construction industry in our country to create greater economic and social benefits.

\section{References}

[1]Luo Jiaqiang, Ying Danning, Management Analysis of Construction Organization and Construction Site Arrangement[J].Architectural

Knowledge, 2016, 36(01):132.

[2]Chen Kaifeng, Analysis of Safety Management of Civil Engineering Construction[J].Min Ying Ke Ji,2016, (06):144.

[3]Cai Zehuan, Talking about the Importance of Project Supervision in the Early Stage of Construction Project[J].Building Safety,2016 , 31(09):42-43. 